\title{
VIDEO-ASSISTED ANAL FISTULA TREATMENT: TECHNICAL CONSIDERATIONS AND PRELIMINARY RESULTS OF THE FRST BRAZLIAN EXPERIENCE
}

\author{
Tratamento cirúrgico videoassistido da fístula anorretal: considerações sobre a técnica e resultados preliminares da \\ primeira experiência brasileira
}

Carlos Ramon Silveira MENDES, Luciano Santana de Miranda FERREIRA, Ricardo Aguiar SAPUCAIA, Meyline Andrade LIMA, Sergio Eduardo Alonso ARAUJO

From Hospital Santa Izabel, Santa Casa de Misericórdia da Bahia, Salvador, BA, Brazil.

HEADINGS - Rectal fistula. Surgical procedures. Minimally invasive. Fecal incontinence. Crohn's disease.
ABSTRACT - Backgroung: Anorectal fistula represents an epithelized communication path of infectious origin between the rectum or anal canal and the perianal region. The association of endoscopic surgery with the minimally invasive approach led to the development of the video-assisted anal fistula treatment. Aim: To describe the technique and initial experience with the technique video-assisted for anal fistula treatment. Technique: A Karl Storz video equipment was used. Main steps included the visualization of the fistula tract using the fistuloscope, the correct localization of the internal fistula opening under direct vision, endoscopic treatment of the fistula and closure of the internal opening which can be accomplished through firing a stapler, cutaneous-mucosal flap, or direct closure using suture. Results: The mean distance between the anal verge and the external anal orifice was $5.5 \mathrm{~cm}$. Mean operative time was $31.75 \mathrm{~min}$. In all cases, the internal fistula opening could be identified after complete fistuloscopy. In all cases, internal fistula opening was closed using fullthickness suture. There were no intraoperative or postoperative complications. After a 5-month follow-up, recurrence was observed in one (12.5\%) patient. Conclusion: Video-assisted anal fistula treatment is feasible, reproducible, and safe. It enables direct visualization of the fistula tract, internal opening and secondary paths.

\section{Correspondence: \\ Carlos Ramon Silveira Mendes \\ E-mail: proctoramon@hotmail.com \\ Financial source: none \\ Conflicts of interest: none}

Received for publication: 05/11/2013 Accepted for publication: 19/12/2013

DESCRTORES - Fístula retal. Procedimentos cirúrgicos minimamente invasivos. Incontinência fecal. Doença de Crohn.
RESUMO - Racional: A fístula anorretal é um trajeto epitelizado que estabelece comunicação de origem infecciosa entre o reto ou canal anal com a região perianal. Representa a fase crônica do abscesso anorretal. A associação da videocirurgia com o procedimento minimamente invasivo levou ao desenvolvimento do tratamento cirúrgico videoassistido da fístula anorretal anal). Objetivo: Descrever a técnica empregada na experiência preliminar nos primeiros casos realizados no Brasil. Técnica: As principais etapas da operação são a visualização do trajeto fistuloso através da fistuloscopia sob irrigação empregando equipamento específico Karl Storz, a correta localização do orifício interno sob visão direta, o tratamento endoscópico da fístula por eletrocoagulação e o tratamento do orifício interno que pode ser feito por grampeador, avanço de retalho mucoso ou sutura simples. Resultados: A distância entre a rima anal e o orifício externo foi de 5,5 cm. O tempo operatório foi de 31,75 (18-45) min em média. Em todos os casos, o orifício interno pôde ser identificado após fistuloscopia completa que foi tratado por meio de sutura simples. Não ocorreram complicações intra ou pósoperatórias. Após seguimento de cinco meses, um (12,5\%) caso evoluiu com recidiva. Conclusão: O tratamento videoassistido da fístula anorretal demonstrou-se factível, seguro e reprodutível. Possibilita estudo direto de todo o trajeto fistuloso conseguindo identificação de trajetos acessórios bem como do orifício interno.

\section{INTRODUCTION}

A norectal fistula constitutes an epithelized path establishing a communication between the rectum or anal canal and the perianal region. In up to $90 \%$ of the cases, the origin of the fistula is cryptoglandular. In only $10 \%$ Crohn's disease, trauma, malignancies, infection, or radiation therapy can be the cause of disease ${ }^{14}$. 
Fistula incidence is estimated in 8.6 per 100,000 individuals with predominance in males by $2: 1$. The disease is more frequent between the third and fifth decade of life ${ }^{10}$. The clinical manifestations are anal itching, discomfort and pain associates to a recurrent mucopurulent discharge sometimes with blood. The diagnosis is usually made by clinical history and physical examination. Diagnostic confirmation and obtaining additional information about the path, degree of sphincter involvement and presence of associated collections are usually performed selectively using endoanal ultrasound and dedicated magnetic resonance imaging.

Healing of anorectal fistula can only be achieved through surgery. The main objectives of surgical treatment include symptom abolishment and preservation of anal continence. The most often used techniques include one-step fistulotomy or fistulectomy and two-step fistulotomy with cutting or drainage seton placement. One or two-step fistulotomies presuppose sphincter transection. Therefore, an unpredictable degree of sphincter dysfunction must be expected after traditional surgical treatment of anal fistula ${ }^{4}$.

The need to reduce or abolish aggression to anal sphincters has changed the operative way on anal fistula. The use of collagen plug, fibrin glue, mucosal flap advancement techniques, and ultimately the ligation of intersphincteric fistula tract (LIFT) aim to avoid muscle injury during surgery.

The combination of a videoendoscopic approach to a minimally invasive procedure led to the proposal of the video-assisted anal fistula treatment (VAAFT) as described by Meinero in $2006^{7}$. One of the main steps to the successful surgical treatment of anorectal fistula is the exact location of the internal fistula opening. VAAFT uses an innovative feature, a rigid fistuloscope for the correct location of the internal opening and to study the fistulous tract looking for collections or accessory paths. One of the major potential benefits of VAAFT technique is to undertake a procedure without direct trauma to the anal sphincters. Moreover, it results in very small surgical wounds ${ }^{4-}$ 7,11 . The use of the traditional techniques for the surgical treatment of anal fistulas are associated to a postoperative risk of fecal incontinence up to $45 \%$. VAAFT does not affect fecal continence; however, it may be associated with a recurrence rate of $30 \%^{7}$. However, reoperations may be conducted using the same technique.

The objective of this paper is to describe the technique and initial experience with the VAAFT technique for anal fistula treatment and the preliminary experience with the treatment of anorectal fistula in Brazil by this method.

\section{TECHNIQUE}

All aspects of this study were approved by the Ethics Committee at Hospital Santa Izabel (Salvador, BA). All patients have fulfilled an informed consent preoperatively.

All patients were operated on at the Coloproctology Unit at Hospital Santa Izabel (Salvador, BA) by two of the authors (CRSM and LSMF). Eight VAAFT operation for treatment of complex anorectal fistulas were conducted in July 2013.

The inclusion criteria were the diagnosis of complex fistulas (which were defined as not amenable to treatment by simple fistulotomy). In all cases, a cryptoglandular etiology was the clinically diagnosed.

The exclusion criterion was the suspicion or diagnosis of Crohn's disease, malignancy, or history of pelvic radiotherapy.

None of the selected cases had undergone diversion stoma.

Preoperative clinical assessment and colonoscopy was performed in all cases. Magnetic resonance imaging was obtained in all patients. The Parks' classification for anorectal fistulas was used. After surgical treatment, clinical assessment was conducted after 15 days and two months, and then, after six and 12 months. Patients were operated under spinal anesthesia. Antibioticotherapy was used in all cases.

The VAAFT technique was performed with the use of the equipment manufactured by Karl Storz (Tuttlingen, Germany - Figure 1) which was connected to a camera as part of a complete surgical video-endoscopy equipment.

The kit consisted of a rigid fistuloscope, a monopolar electrode, one brush and one endoscopic forceps. The fistuloscope was equipped with an $8^{\circ}$-angled rigid telescope. Its diameter was $3.3 \times 4.7 \mathrm{~mm}$. Its operative length wass $18 \mathrm{~cm}$. The fistuloscope has an optical channel and a working/irrigation channel. The working/irrigation channel has two taps. One of them is connected to the irrigation solution (glycine-mannitol 1-1.5\%). The complete set is provided with a handle that facilitates maneuvering. The fistuloscope was connected to the video-endoscopy set. The complete operation was video-recorded.

VAAFT technique is divided in two stages: a diagnostic one and an operative one.

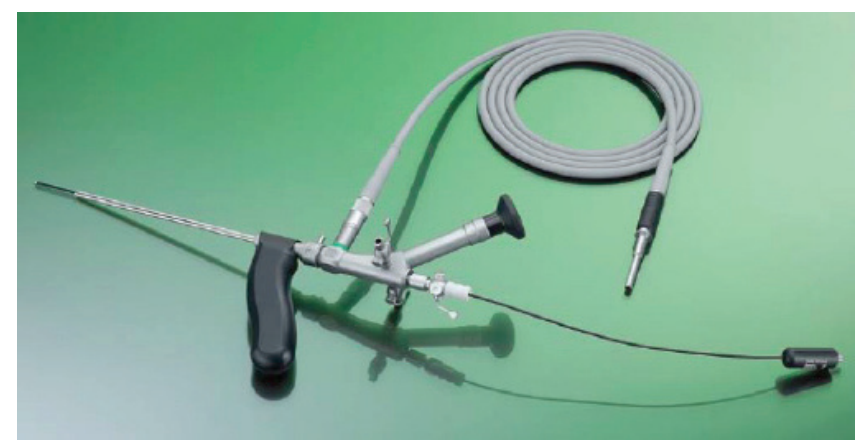

FIGURE 1 - Equipment for VAAFT 


\section{Diagnosis}

The purpose of the diagnostic stage is the correct identification of the fistula tract form the external to the inner opening and accessory tracts.

The patient is placed in the lithotomy position after spinal block anesthetic technique. The fistuloscope is then inserted through the external opening. Under continuous infusion of glycine/ mannitol solution, the fistuloscope is advanced through the fistula tract with direct visualization of the lumen.

The identification of incomplete secondary fistula tracts (meaning not associated with an external opening) is one of the major advantages of fistuloscopy when compared to conventional surgical exploration using a probe or methylene blue infection. However, advancing the fistuloscope through the tract may sometime be difficult due to fibrosis located at the external orifice. A small incision in the external opening may solve the problem.

The handle fitted to the fistuloscope helps changing direction during the diagnostic phase. Optimal vision of the lumen of the fistula is ensured by the continuous jet of irrigation solution reaching as far as the internal opening. The final step of the diagnostic phase is passing the internal opening with the fistuloscope. At this time, the surgeon may reduce the $O R$ illumination and trans-illuminate the final portion of the fistula to the level of the internal opening. Moreover, the assistant surgeon may use retractors to better expose it. After identification of the internal opening, two stiches may be used to facilitate further identification.

\section{Treatment}

The steps that comprise the treatment phase $^{7}$ are destruction and cleaning of the fistula tract, followed by management of the internal opening.

For fistula tract destruction, the monopolar electrode is activated all the way under direct vision resulting in cauterization of the tract centimeter-bycentimeter form the level of the external orifice to the level of the internal opening. Jet irrigation and brush abrasion are used to remove necrotic material (Figure 2).

The closure of the internal opening is another critical step to the cure of anal fistula. Its performance should be carefully conducted during surgery employing VAAFT. Alternatively, repair of the internal opening can be undertaken by firing and endoscopic stapler, or by using mucosal advancement flap. Ultimately, simple suture may be used. Different degrees of fibrosis observed at the level of the internal opening may level can hinder the application of the stapler (Figure 3).

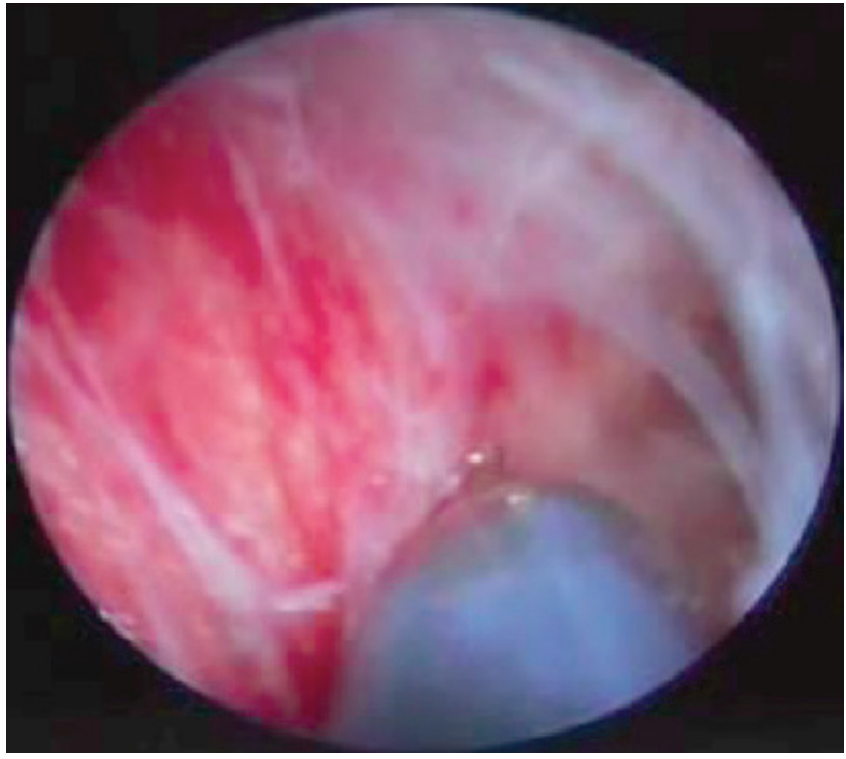

FIGURE 2 - Destruction of the fistula tract using the monopolar electrode

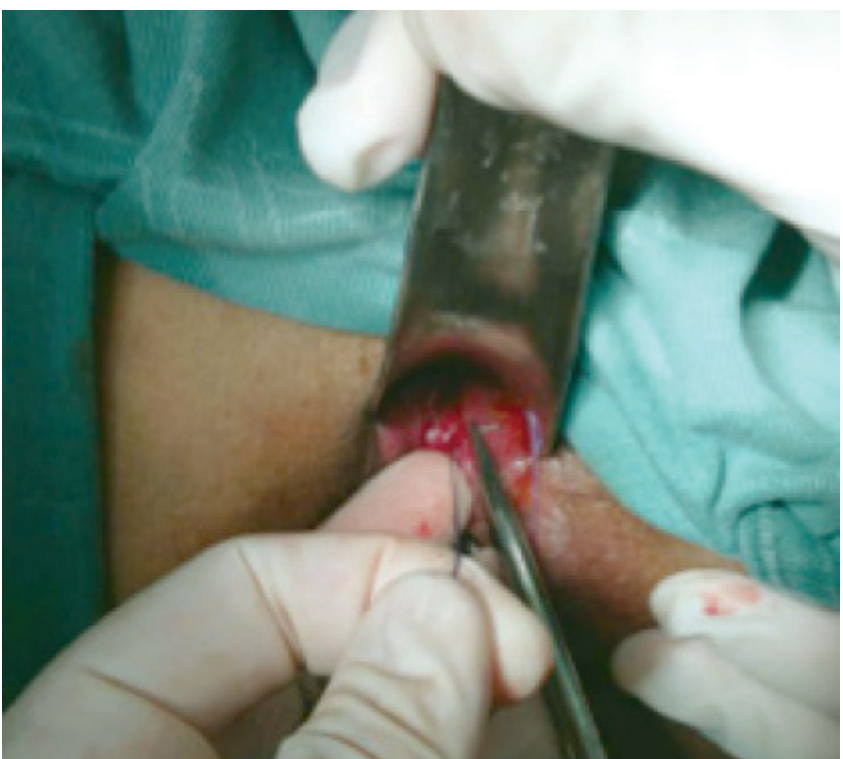

FIGURE 3 - Closure of internal fistula opening with stitches

\section{RESULTS}

Only one (12.5\%) patient was female. The mean age was 43 (29-66) years. The average distance between the internal and the external anal opening was $5.5(4-9) \mathrm{cm}$. Regarding the classification, six were considered trans-sphincteric fistulas and two, extra-sphincteric. There were two cases of recurrent fistulas with more than one external orifice. The mean duration of the operative procedure was 31.7 (18-45) $\mathrm{min}$. The internal opening could be identified in all cases. Simple suturing closure of the internal opening was performed in all cases. 
There were no intraoperative or late complications.

The operation was considered a simple procedure. The perception during the operations was of a small perianal aggression. It was observed that in the fistulas with a short tract, handling of the equipment was more difficult.

After a mean follow-up of five months, recurrence was observed in one (12.5\%) case.

\section{DISCUSSION}

In this preliminary trial, it was demonstrated that the technique of VAAFT for the surgical treatment of complex anorectal fistula is safe, effective and reproducible. The main benefits are the complete preservation of sphincter muscles, ability to properly study the entire fistula and accessory tracts and collections, identify with high accuracy the location of the internal opening, and to offer treatment with minimal perianal trauma.

To date, there are few studies on the surgical treatment of anorectal fistula with use of VAAFT in the literature. The experience reported in this study is the pioneer and the largest in our country. Correct identification of the fistula tract and mainly its internal opening are the characteristics most potentially associated with successful surgical treatment ${ }^{3}$ techniques.

Simple fistulas diagnosed in patients with decreased sphincter involvement are preferably treated by one-stage fistulotomy. Although associated with high effectiveness, this technique may not be used in patients with complex fistula due to increased risk of fecal continence disorders. For the management of complex anal fistula, the use of surgical techniques associated with controlled, progressive, or preferably absent muscle transection is demanded.

The main obstacle to the use of muscle-sparing techniques is the highest recurrence rate. Complex fistulas treated by mucosal flap are associated with up to a $54 \%$ recurrence rate ${ }^{8-9}$. The use of fibrin adhesive techniques is associated to recurrence in up to $50 \%{ }^{2,12}$. In spite of their higher recurrence rates, both techniques may be repeated. The LIFT technique has been used more recently for the management of complex anal fistula. The success rate associated to this technique in its prime report was $97 \%$. The same principle of exclusion of the internal opening during LIFT is followed during VAAFT. However, during LIFT, surgeons may not study the fistula tract. Therefore, the location of collections or potentially identifiable residual abscesses during LIFT is precluded ${ }^{(6,13)}$.

VAAFT technique surgical principles include the precise identification of the fistula internal opening associated to its closure, and complete destruction of the fistula tract. To date, the largest series was published by Meinero and Mori ${ }^{7}$, proponents of operative technique. In his first publication, 136 patients with complex fistulas were operated on between May 2006 and May 2011. The highest incidence was found in males (70\%). The mean population age was 42 years, similar what was found in the present study. During preliminary experience, no intraoperative bleeding or infectious complications were observed. However, was observed one case of urinary dysfunction and postoperative edema in the scrotum possibly due to infiltration by the irrigation solution. Patient recovery was uneventful. All patients were discharged at the day of surgery. Pain complaints were mild. Meinero and Mori ${ }^{7}$ reported primary fistula healing in $73.5 \%$ of patients after three months. In these patients, 26.5 $\%$ could be re-operated by using VAAFT again. The final fistula healing rate for this sample was $87.1 \%$.

The real innovation associated with the VAAFT technique is the precise identification of the fistula anatomy and of the internal opening by fistuloscopy and fulguration of the tract walls under direct vision. Regarding the main limitations associated to the technique during this preliminary experience, was observed that progression of the fistuloscope may be hampered by the presence of tracts of too sharp rise from the main path. Moreover, the sensibility of the fistuloscopy for the diagnosis of secondary tracts remains unknown since the gold standards techniques for the definition of fistula anatomy remain resonance, ultrasound and intraoperative exploration using operative probes and methylene blue dye. Another undefined aspect of the technique is actual role of electrocoagulation diathermy (destruction) of the fistula tract in the management of his disease. Chivate ${ }^{1}$ believes that the consequences of this step are unknown, and that it may be associated with collateral thermal damage, compromising healing and favoring recurrence. In the present study, was not observed complications like postoperative cellulitis that could prove this author's concerns.

Another important technical discussion is related to the options for managing the fistula internal opening. Firing of an endoscopic stapler represents a truly attractive option. However, fibrosis at the level of the internal opening may preclude this option. Moreover, there is also concern about the level of discomfort that stapling in the anal canal/distal rectum may rise to the patient in the immediate postoperative period. Ultimately, dehiscence rates of the internal opening closure with this approach remain unknown.

Regarding the long-term results of anal fistula healing associated to the VAAFT technique, they simply may not be addressed yet. For most cases 
operated on by Meinero and Mori? , the duration of postoperative follow-up was less than six months. Moreover, it was less than 12 months for half the studied sample.

Rigid fistuloscopy remains the most innovative aspect associated with VAAFT. Whether and to what extent this diagnostic and therapeutic (electrocoagulation of the tract) resource will affect long-term fistula healing rates remains undefined. However, there might be consensus on the minimally invasive nature of the approach since reduced operative wounds are generated in the perianal region with the technique, and the approach to the internal opening is accomplished exclusively via a transanal route.

\section{CONCLUSION}

The technique of VAAFT for treating complex anal fistulas is feasible, reproducible and safe. It enables direct visualization of the fistula tract, internal opening and secondary paths

\section{REFERENCES}

1. Chivate, S. D. Comment on Meinero and Mori: Video-assisted anal fistula treatment (VAAFT): a novel sphincter-saving procedure to repair complex anal fistulas. Tech Coloproctol 2012; 16(6): 465466; discussion 467; author reply 469-470.

2. Christoforidis, D., D. A. Etzioni, S. M. Goldberg, R. D. Madoff and A. Mellgren. Treatment of complex anal fistulas with the collagen fistula plug. Dis Colon Rectum 2008; 51(10): 1482-1487.
3. Garcia-Aguilar, J., C. Belmonte, W. D. Wong, S. M. Goldberg and R. $D$. Madoff. Anal fistula surgery. Factors associated with recurrence and incontinence. Dis Colon Rectum 1996; 39(7): 723-729.

4. Jacob, T. J., B. Perakath and M. R. Keighley. Surgical intervention for anorectal fistula. Cochrane Database Syst Rev 2010. (5).

5. Lupinacci, R. M., C. Vallet, Y. Parc, N. Chafai and E. Tiret. Treatment of fistula-in-ano with the Surgisis((R)) AFP(TM) anal fistula plug. Gastroenterol Clin Biol 2010; 34(10): 549-553.

6. Malik, A. I. and R. L. Nelson. Surgical management of anal fistulae: a systematic review. Colorectal Dis 2008; 10(5): 420-430.

7. Meinero, P. and L. Mori. Video-assisted anal fistula treatment (VAAFT): a novel sphincter-saving procedure for treating complex anal fistulas. Tech Coloproctol 2011; 15(4): 417-422.

8. Mizrahi, N., S. D. Wexner, O. Zmora, G. Da Silva, J. Efron, E. G. Weiss, A. M. Vernava, 3rd and J. J. Nogueras. Endorectal advancement flap: are there predictors of failure? Dis Colon Rectum 2002; 45(12): 1616-1621.

9. Ozuner, G., T. L. Hull, J. Cartmill and V. W. Fazio. Long-term analysis of the use of transanal rectal advancement flaps for complicated anorectal/vaginal fistulas. Dis Colon Rectum 1996; 39(1): 10-14.

10. Ritchie, R. D., J. M. Sackier and J. P. Hodde. Incontinence rates after cutting seton treatment for anal fistula. Colorectal Dis 2009; 11(6): 564-571.

11.Schwandner, O. Video-assisted anal fistula treatment (VAAFT) combined with advancement flap repair in Crohn's disease. Tech Coloproctol 2013; 17(2): 221-225.

12. Sentovich, S. M. Fibrin glue for all anal fistulas. J Gastrointest Surg 2001; 5(2): 158-161.

13. Sentovich, S. M. Fibrin glue for anal fistulas: long-term results. Dis Colon Rectum 2003; 46(4): 498-502.

14. Shanwani, A., A. M. Nor and N. Amri. Ligation of the intersphincteric fistula tract (LIFT): a sphincter-saving technique for fistula-in-ano. Dis Colon Rectum 2010; 53(1): 39-42

15. Steele, S. R., R. Kumar, D. L. Feingold, J. L. Rafferty, W. D. Buie, C. Standards Practice Task Force of the American Society of and S. Rectal. Practice parameters for the management of perianal abscess and fistula-in-ano. Dis Colon Rectum 2011; 54(12): 1465-1474.

16.Zbar, A. P. Video-assisted anal fistula treatment (VAAFT): a novel sphincter-saving procedure to repair complex anal fistulas by Piercarlo Meinero and Lorenzo Mori. Tech Coloproctol 2011; 15(4): 423-424. 